\title{
Methane Activation and Transformation on Polyoxometalates
}

\author{
Frédéric Lefebvre, Eva Grinenval, and Piotr Putaj \\ Université de Lyon ICL, C2P2 UMR 5265 LCOMS (CNRS-CPE-Université Lyon 1), 43 Boulevard du 11 Novembre 1918, \\ 69616 Villeurbanne, France \\ Correspondence should be addressed to Frédéric Lefebvre; lefebvre@cpe.fr
}

Received 9 November 2012; Accepted 19 December 2012

Academic Editor: Jianqin Zhuang

Copyright (C) 2013 Frédéric Lefebvre et al. This is an open access article distributed under the Creative Commons Attribution License, which permits unrestricted use, distribution, and reproduction in any medium, provided the original work is properly cited.

Methane is activated at moderate temperature on polyoxometalates, leading to the evolution of hydrogen and the formation of a methoxy species which has been characterized by solid-state ${ }^{13} \mathrm{C}$ CP-MAS NMR. In the case of a molybdic polyoxometalate, the methyl group is linked to an edge-shared oxygen atom of the polyoxometalate. Upon heating, it reacts with oxygens of the polyoxometalate resulting in the formation of formyl species and then carbon dioxide and a reduction of molybdenum. Upon treatment with water, only traces of methanol can be detected.

\section{Introduction}

Interest of the scientists in the direct methane conversion does not seem to falter as the 21 st century world faces the perspective of dwindling petrol supplies $[1,2]$. However, an economically feasible methane valorization system by its partial oxidation to methanol or formaldehyde, though tempting, remains still rather an elusive perspective. Indeed, methane is notorious for its chemical inertness, justified by its symmetry and high $\mathrm{C}-\mathrm{H}$ primary bond stability $\left(440 \mathrm{~kJ} \cdot \mathrm{mol}^{-1}\right)$. Unfortunately, once activated, it is rare to obtain the partial oxidation products as they are more reactive than the substrate itself and the reaction proceeds rapidly leading to a $\mathrm{CO}_{2}$ release. Generally, redox properties are claimed to be responsible for the catalysts performance in oxidation reactions [3] although the acid-base strength was suggested to play a crucial role in the $\mathrm{C}-\mathrm{H}$ activation initial step [4]. As the methane "neutral" chemical character makes it easily adaptable to activator's properties, various $\mathrm{C}-\mathrm{H}$ dissociation paths were evidenced [5-7]. If the task was not complicated enough, another trend should also be taken into account when developing catalytic oxidation systems-while chemistry becomes more and more environmentally aware, combinations of noble metal compounds and highly toxic reaction media [8-10] are bound to give way to "greener" and cheaper alternatives. Polyoxometalates seem a reasonable choice in this respect.

The polyoxometalatesconstitute a well-known class of compounds, based on transition metals (Mo, W, V, and to a lesser degree $\mathrm{Ta}$ and $\mathrm{Nb}$ ) and oxygen, and could be perceived as discreet analogues of metal oxide surfaces [11]. They are widely used in homogenous and heterogenous catalyses, due to their pronounced and tunable acidic and redox properties. As they are easily soluble in polar solvents, they can be used in a lot of homogeneous reactions involving polar molecules. On the other hand, there are only very limited examples of applications of pure solid heteropolyoxometalates in heterogenous catalysis, due to their very low specific surface area (only a few $\mathrm{m}^{2} \cdot \mathrm{g}^{-1}$ ). These applications are limited mostly to polar molecules which can react not only on the surface of the crystals but also in the first layers of the bulk, thus overcoming this issue (the "pseudoliquid phase").

Various approaches were proposed to solve the problem of low surface areas of polyoxometalates: (i) they can be deposited by impregnation on various carriers such as silica, alumina, or carbon. However, physicochemical studies showed that this method can lead to a weakening of the purely Brønsted acid sites [12-15]; (ii) the oxide support 
(mainly silica) is first modified by anchoring amine groups, for example, by reaction with $\mathrm{NH}_{2} \mathrm{RSi}(\mathrm{OEt})_{3}$. Reaction with the heteropolyacid leads to protonation of the amine and formation of well-dispersed polyoxometalates on the support but most of the acidity is lost; (iii) the polyoxometalates can be dispersed inside the support during its preparation, for example, during the condensation of $\mathrm{Si}(\mathrm{OEt})_{4}$ moieties. A lot of studies reported the use of this strategy [16] which can lead to systems more active than the homogeneous ones, mainly due to the increase of the local concentration of the reagents near the polyoxometalates [17]; (iv) the polyoxometalate can be dispersed on a $\mathrm{Cs}^{+}, \mathrm{K}^{+}, \mathrm{NH}_{4}{ }^{+}$, or $\mathrm{Rb}^{+}$salt of $\left[\mathrm{PM}_{12} \mathrm{O}_{40}\right]^{3-}$ [18]. Indeed, these insoluble salts have a very high surface area (more than $100 \mathrm{~m}^{2} \cdot \mathrm{g}^{-1}$ ) and the acid can be deposited on their surface and stabilized by interactions with the cations. This results in solids with formulas such as $\mathrm{A}_{x} \mathrm{H}_{3-x} \mathrm{PM}_{12} \mathrm{O}_{40}$ with $\mathrm{A}=\mathrm{Cs}, \mathrm{K}, \mathrm{NH}_{4}$, $\mathrm{Rb}$ and $\mathrm{M}=\mathrm{Mo}$, W.

The light alkanes oxidation requires redox and sometimes acidic features of the catalytic system, explaining why polyoxometalates have been extensively studied over the years. As a result, numerous gas- or liquid-phase catalytic systems were described. A pioneering work on the gas phase methane oxidation on supported polyoxometalates was reported by Kasztelan and Moffat $[19,20]$. Various molybdic polyoxometalates were found to be efficient for the partial methane oxidation with $\mathrm{N}_{2} \mathrm{O}$ at elevated temperatures $\left(500^{\circ} \mathrm{C}\right.$ and higher), whereas tungstic ones were inactive. Cesium salts of polyoxometalates functionalized with Pd were successfully used by Mizuno et al. in the oxidation of alkanes with a $\mathrm{O}_{2}-\mathrm{H}_{2}$ mixture $[21,22]$. In that case, the activity was probably related to the in situ generation of $\mathrm{H}_{2} \mathrm{O}_{2}$ on the Pd particles. On silicasupported silicomolybdic acid, a partial methane oxidation to formaldehyde under water vapour was observed at high temperature [23]. These operating conditions corresponded to the decomposition temperature of the polyoxometalate which was then in equilibrium (due to the presence of water) with other species. This resulted in the formation of active oxygen atoms which could oxidize methane. Finally, Pei et al. [24] and Benlounes et al. [25] used polyoxometalates as precursors of highly dispersed mixed metal oxides, that showed higher activities in methane oxidation with $\mathrm{O}_{2}$ at atmospheric pressure than oxides obtained from classical impregnation [26]. This reaction has also been studied in the liquid phase on other alkanes and a recent review describes the state of the art of liquid phase oxidation of hydrocarbons using vanadium-based polyoxometalates [27].

Despite all these efforts, only fragmentary pieces of information are available about the light alkanes oxidation reaction mechanism (or mechanisms, for that matter) on polyoxometalates; therefore, formulations of the catalytic systems are still mostly empirical. The aim of this paper is to study the methane oxidation on polyoxometalates in order to clearly define consecutive stages of the process and to determine their limiting (or not) character for this reaction. We choose to work on polyoxometalates supported on silica (in order to increase the amount of surface species) but the conclusions drawn here can be extended to the other types of catalysts (e.g., bulk or alkaline salts).

\section{Experimental}

2.1. Materials. Silicomolybdic acid $\mathrm{H}_{4} \mathrm{SiM}_{12} \mathrm{O}_{40} \cdot x \mathrm{H}_{2} \mathrm{O}(99+$ $\%$, Strem), silicotungstic acid $\mathrm{H}_{4} \mathrm{SiW}_{12} \mathrm{O}_{40} \cdot x \mathrm{H}_{2} \mathrm{O}(99.9+\%$, Aldrich), phosphomolybdic acid $\mathrm{H}_{3} \mathrm{PMo}_{12} \mathrm{O}_{40} \cdot x \mathrm{H}_{2} \mathrm{O}(99+$ $\%$, Aldrich) and phosphotungstic acid $\mathrm{H}_{3} \mathrm{PW}_{12} \mathrm{O}_{40} \cdot x \mathrm{H}_{2} \mathrm{O}$ $\left(99+\%\right.$, Aldrich) were used as received. $\mathrm{H}_{4} \mathrm{PVMo}_{11} \mathrm{O}_{40}$ and $\mathrm{H}_{5} \mathrm{PV}_{2} \mathrm{Mo}_{10} \mathrm{O}_{40}$ were synthesized from $\mathrm{MoO}_{3}$ (99\%, Acros), $\mathrm{V}_{2} \mathrm{O}_{5}$ (99.6\%, Acros) and phosphoric acid $\mathrm{H}_{3} \mathrm{PO}_{4}$ (85 wt.\%, Aldrich) according to Berndt et al. [28] and characterized by IR, elemental analyses and ${ }^{31} \mathrm{P}$ solution NMR. For simplicity, the polyoxometalates will be denoted in the following as HSiMo, HSiW, HPMo, HPW, HPVMo, and $\mathrm{HPV}_{2} \mathrm{Mo}$, for $\mathrm{H}_{4} \mathrm{SiMo}_{12} \mathrm{O}_{40}, \mathrm{H}_{4} \mathrm{SiW}_{12} \mathrm{O}_{40}, \mathrm{H}_{3} \mathrm{PMo}_{12} \mathrm{O}_{40}, \mathrm{H}_{3} \mathrm{PW}_{12} \mathrm{O}_{40}$, $\mathrm{H}_{4} \mathrm{PVMo}_{11} \mathrm{O}_{40}$, and $\mathrm{H}_{5} \mathrm{PV}_{2} \mathrm{Mo}_{10} \mathrm{O}_{40}$, respectively. Silica (flame Aerosil from Degussa, $200 \mathrm{~m}^{2} \cdot \mathrm{g}^{-1}$ ) was compacted and sieved before use. Methane- ${ }^{13} \mathrm{C}$ and methanol- ${ }^{13} \mathrm{C}(99 \%$ atom ${ }^{13} \mathrm{C}$, Aldrich) were used without further purification. If not stated otherwise, all samples were kept under dry inert atmosphere in the glovebox. All manipulations were performed under vacuum or Ar atmosphere using standard Schlenk techniques.

2.2. Samples Preparation. A mixture of heteropolyacid dissolved in water $(10 \mathrm{~mL})$ and silica was stirred vigorously until evaporation of all the solvent at RT. The powder (containing $60 \%$ wt. of polyoxometalate) was collected and ground in the mortar. This material was then treated under high vacuum $\left(10^{-5}\right.$ Torr) for 2 hours at $200^{\circ} \mathrm{C}$ to dehydrate the polyoxometalate and afterwards heated for another 2 hours at $200^{\circ} \mathrm{C}$ under dry $\mathrm{O}_{2}$ to reoxidize any clusters that might have been reduced upon previous manipulations (after this treatment the color of the samples returned to the initial one).

2.3. Temperature-Programmed Reaction Experiments. The sample (250 mg of solid) was loaded in a continuous tubular reactor and heated at a rate of $50^{\circ} \mathrm{C} / \mathrm{h}$ from 40 to $500^{\circ} \mathrm{C}$ under methane flow $(5 \mathrm{~mL} / \mathrm{min})$ or methane with air $\left(\mathrm{CH}_{4}: \mathrm{O}_{2}=\right.$ 2 : 3; global gas flow $5 \mathrm{~mL} / \mathrm{min}$ ). The temperature was carefully recorded as a function of time and the composition of the evolved gases was determined online by gaseous chromatography.

2.4. Alkane Adsorption. Typically, the dehydrated and reoxidized POM sample (300 mg) was introduced in a glass reactor of known volume, equipped with an $\mathrm{IR}$ cell ( $\mathrm{CaF}_{2}$ windows) and evacuated until high vacuum $\left(10^{-5}\right.$ Torr $)$ was reached. 200 Torr of methane or propane was then introduced in the reactor and the sample was heated for 12 hours at a given temperature. After cooling down, the residual gases were evacuated and the reactor filled again with 200 Torr of dry oxygen. The sample was then burnt at $500^{\circ} \mathrm{C}$ for 3 hours and the evolved $\mathrm{CO}_{2}$ quantified by means of IR spectroscopy (Nicolet 5700-FT spectrometer in transmission mode with a resolution of $1 \mathrm{~cm}^{-1}$, typical number of scans: 32 ). Control experiments (burning of the supported polyoxometalate in $\mathrm{O}_{2}$ at $500^{\circ} \mathrm{C}$, without alkane exposure and treatment of silica alone by methane) were also performed. 
2.5. ${ }^{13} \mathrm{CH}_{4}$ and ${ }^{13} \mathrm{CH}_{3} \mathrm{OH}$ Adsorption. Similarly, the dehydrated and reoxidized POM sample was put in a glass reactor and evacuated until high vacuum $\left(10^{-5}\right.$ Torr $)$ was reached. 500 Torr of ${ }^{13} \mathrm{C}$-enriched methane was introduced to the reactor and the sample was heated during 2 hours at $200^{\circ} \mathrm{C}$ (for MAS NMR experiments) or during 12 hours (for desorption of surface species). For methanol adsorption, the sample was cooled to liquid nitrogen temperature and briefly exposed to vapours of methanol. It was allowed to warm up at room temperature over one hour and then evacuated at $60^{\circ} \mathrm{C}$ or $120^{\circ} \mathrm{C}$ during one hour.

2.6. NMR Experiments. In all cases, the zirconia rotors were filled with the samples in a glovebox and tightly closed. The

${ }^{13} \mathrm{C}$ solid state MAS NMR experiments were performed on a Bruker Avance 500 spectrometer equipped with a standard $4 \mathrm{~mm}$ double-bearing probehead. The rotation frequency was set to $10 \mathrm{kHz}$. A typical cross-polarization sequence was used, with $4 \mathrm{~ms}$ contact time and a recycle delay of 1 to $4 \mathrm{~s}$ to allow the complete relaxation of the ${ }^{1} \mathrm{H}$ nuclei (first checked by performing ${ }^{1} \mathrm{H}$ MAS NMR with different recycle delays). All measured chemical shifts are given with respect to TMS as an external reference. The solution NMR spectra were recorded on a Bruker AM-300 spectrometer.

2.7. ESR Experiments. The ESR spectra were recorded on a Bruker Elexsys e500 X-band $(9.4 \mathrm{GHz})$ spectrometer with a high-sensitivity cavity at $110 \mathrm{~K}$. The magnetic field was measured with a gaussmeter.

\section{Results and Discussion}

3.1. Methane Activation on Polyoxometalates. The first step of methane oxidation is the activation of the $\mathrm{C}-\mathrm{H}$ bond, which is generally considered as very difficult. In order to obtain some information on this step, we performed a series of experiments by heating the supported polyoxometalates under methane flow and analyzing the output gases ("temperature-programmed reaction"). We studied both tungstic heteropolyacids (usually used for acid catalysis) and molybdic or vanadomolybdic ones (used in redox reactions).

In addition to methane, only hydrogen and carbon dioxide were observed in the output gases (water was not analyzed). Their amounts as a function of the temperature and of the polyoxometalate are plotted in Figure $1\left(\right.$ for $\left.\mathrm{H}_{2}\right)$ and Figure 2 (for $\mathrm{CO}_{2}$ ).

These data show some interesting features: (i) whatever the polyoxometalate there is evolution of carbon dioxide at moderate temperature (below $300^{\circ} \mathrm{C}$ ) where the polyoxometalate is stable probing that methane is activated in all cases; (ii) only the product of full oxidation is detected, methanol and formaldehyde are not observed; (iii) there is also evolution of hydrogen at quite the same temperatures and at quite the same amounts than $\mathrm{CO}_{2}$.

The key point of these experiments is the evolution of hydrogen in parallel to that of $\mathrm{CO}_{2}$. Indeed, methane activation could, a priori, proceed via different ways:

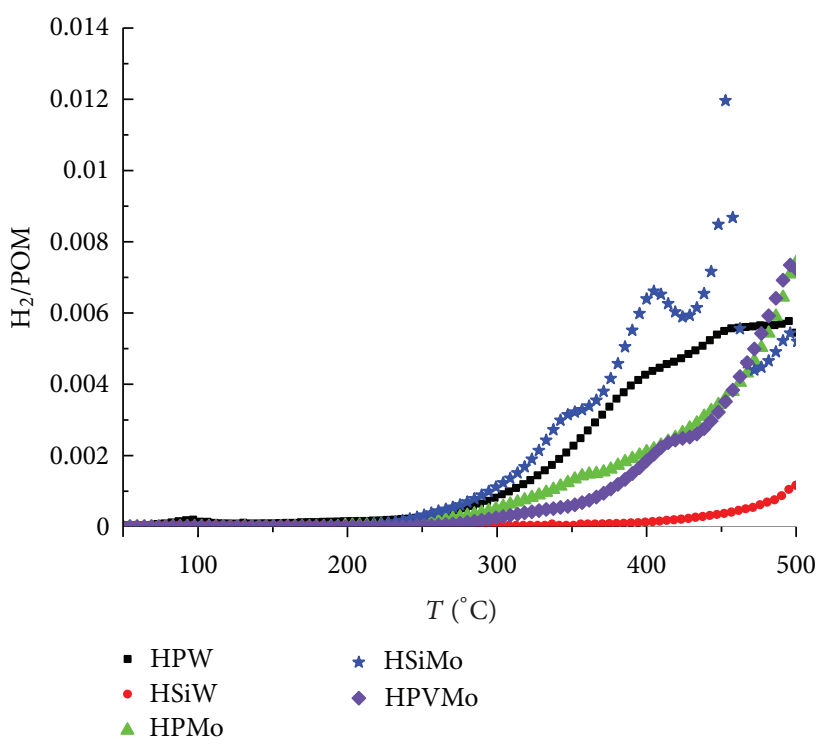

FIGURE 1: $\mathrm{H}_{2}$ release during the reaction of flowing $\mathrm{CH}_{4}$ with various silica-supported polyoxometalates at increasing temperatures.

(i) acid reaction with the protons of the polyoxometalate. This reaction is usually proposed for alkane activation by acid catalysts, such as zeolites, and leads to the evolution of hydrogen:

$$
\mathrm{CH}_{4}+\mathrm{H}^{+} \longrightarrow\left[\mathrm{CH}_{3}^{+}\right]+\mathrm{H}_{2} \uparrow
$$

(ii) Redox reaction with the polyoxometalate. We observed that reaction of silanes with molybdic or vanadomolybdic heteropolyacids led to evolution of lower amounts of hydrogen than expected and to reduction of the polyoxometalate and proposed then such a mechanism $[29,30]$ :

$$
[\mathrm{POM}]+\mathrm{CH}_{4} \longrightarrow[\mathrm{POM}]^{2-}\left[\mathrm{CH}_{3}^{+}\right]\left[\mathrm{H}^{+}\right]
$$

(iii) Homolytic cleavage of the $\mathrm{C}-\mathrm{H}$ bond. This mechanism has never been observed on polyoxometalates:

$$
\mathrm{CH}_{4} \longrightarrow \mathrm{CH}_{3}^{\bullet}+\mathrm{H}^{\bullet}
$$

The evolution of hydrogen shows unambiguously that the acidic pathway is present but the redox one cannot be definitively excluded on the basis of these data.

The $\mathrm{CO}_{2}$ release in these anaerobic conditions shows a strong methane conversion dependence on the polyanion type, with molybdic and vanadomolybdic clusters being the most active (the cumulative values between $\mathrm{RT}$ and $500^{\circ} \mathrm{C}$ for the above experiments are ca. $0.1 \mathrm{CO}_{2}$ per POM for tungstic compounds, ca. one $\mathrm{CO}_{2}$ per molybdic compounds and ca. 2 for vanadomolybdic ones). Since methane is the only gas present, the oxygen atoms of the $\mathrm{CO}_{2}$ molecules come from the polyanion undergoing then a reduction under the reaction conditions. As expected the reducible Mo-based clusters exhibit higher activities than tungstic ones when no other source of oxygen is present. The reactions occurring 

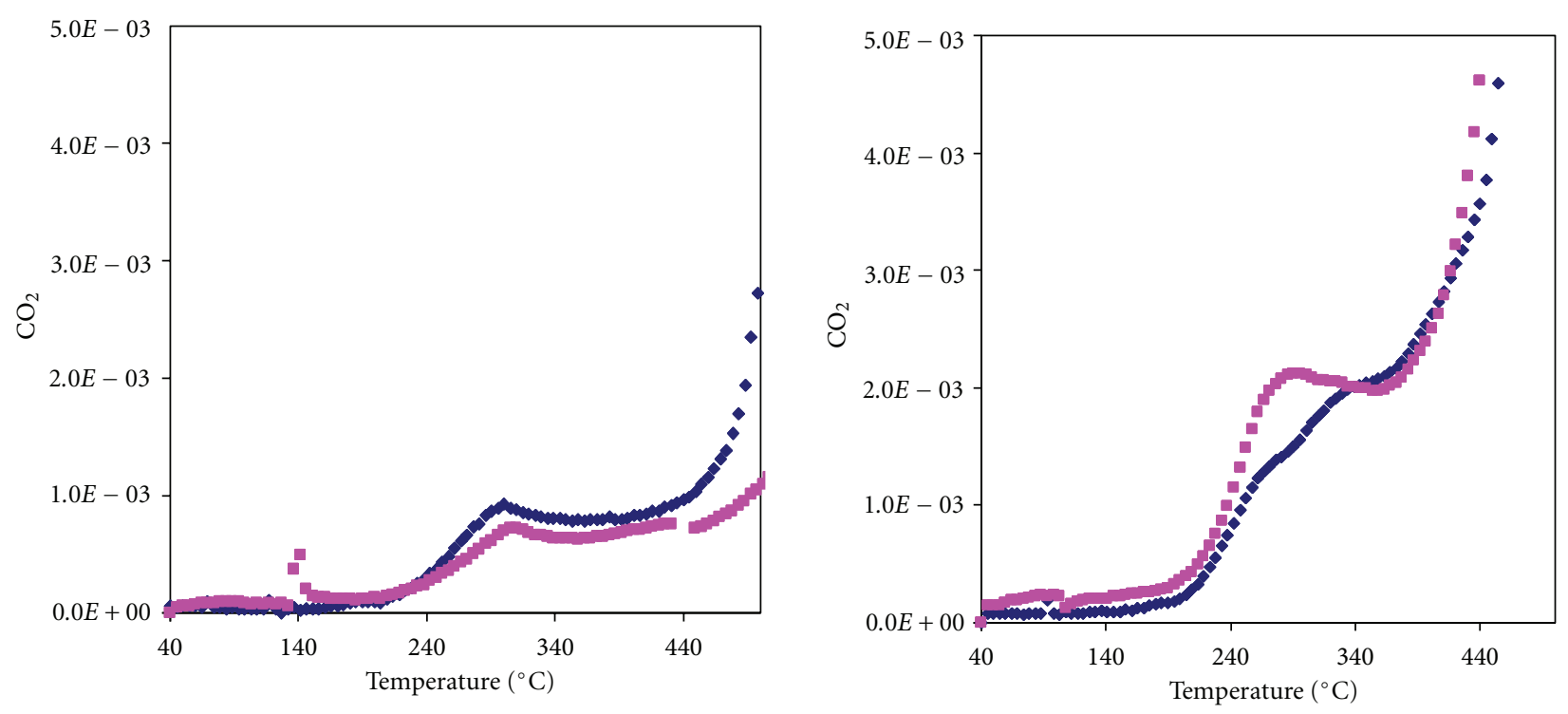

- HSiW

- HPW

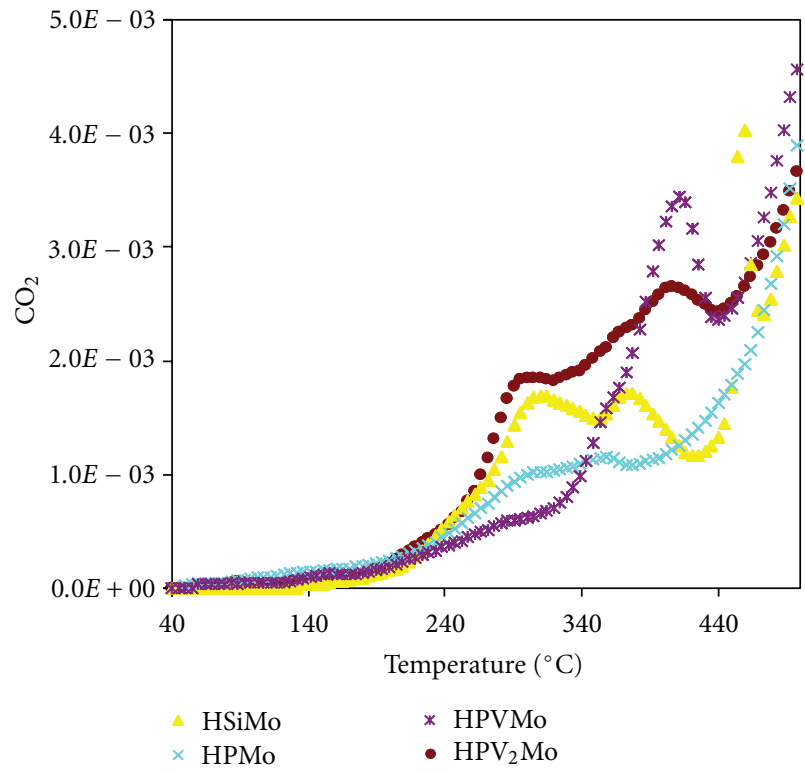

(a)

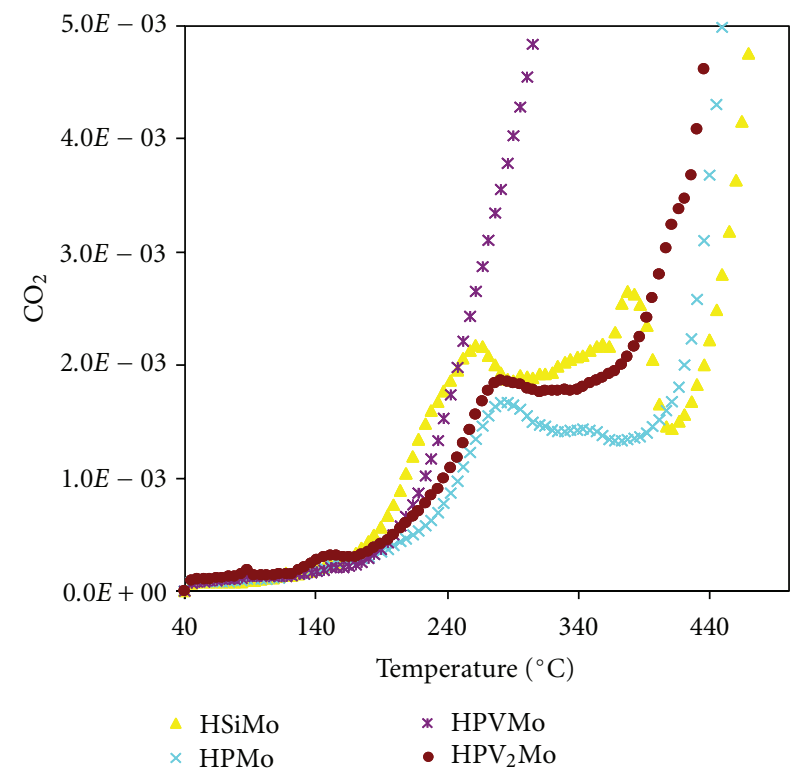

(b)

FIGURE 2: $\mathrm{CO}_{2}$ release during the reaction of flowing $\mathrm{CH}_{4}$ (a) or $\mathrm{CH}_{4}+\mathrm{O}_{2}$ (b) with various silica-supported polyoxometalates at increasing temperatures. All curves are on the same scale.

in that case are then: (i) activation of methane by the polyoxometalate, followed by (ii) oxidation of the "activated methane species" by the oxygen atoms of the polyoxometalate which will be reduced (and eventually decomposed).

In order to have more quantitative information and to determine at what temperature methane was activated, we performed some additional experiments. This study was made on $\mathrm{HSiMo} / \mathrm{SiO}_{2}$. This polyoxometalate was chosen as the above data had shown that a nonnegligible amount of methane was activated (in contrast to tungstic compounds) and because it was stable until a relatively high temperature (in contrast to the vanadomolybdic species). For this purpose, methane was first contacted with the polyoxometalate during 12 hours at a given temperature. The gaseous phase was then removed at room temperature and dry oxygen added to the reaction vessel. Heating at $500^{\circ} \mathrm{C}$ resulted in a complete transformation of all sorbed species into $\mathrm{CO}_{2}$ (and $\mathrm{H}_{2} \mathrm{O}$ ) which was analyzed by means of IR, allowing a quantification of the amount of methane which had been activated (note that this value corresponds to a minimal value as gaseous products formed during the heating under methane are not taken into account). The results are shown in Figure 3 together with those obtained for propane. 


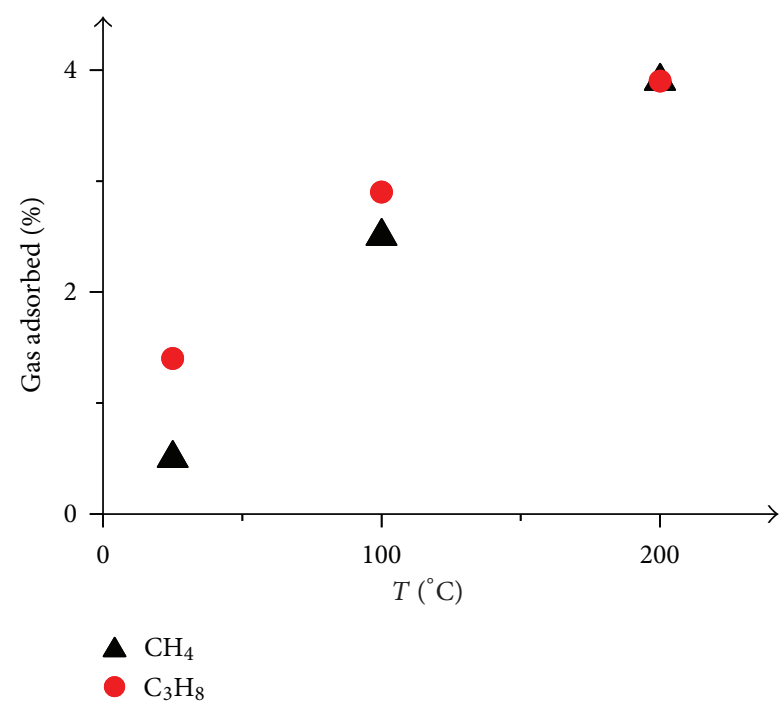

Figure 3: Amount of methane (black triangles) and propane (red circles) adsorbed on $\mathrm{H}_{4} \mathrm{SiMo}_{12} \mathrm{O}_{40} / \mathrm{SiO}_{2}$ at various temperatures.

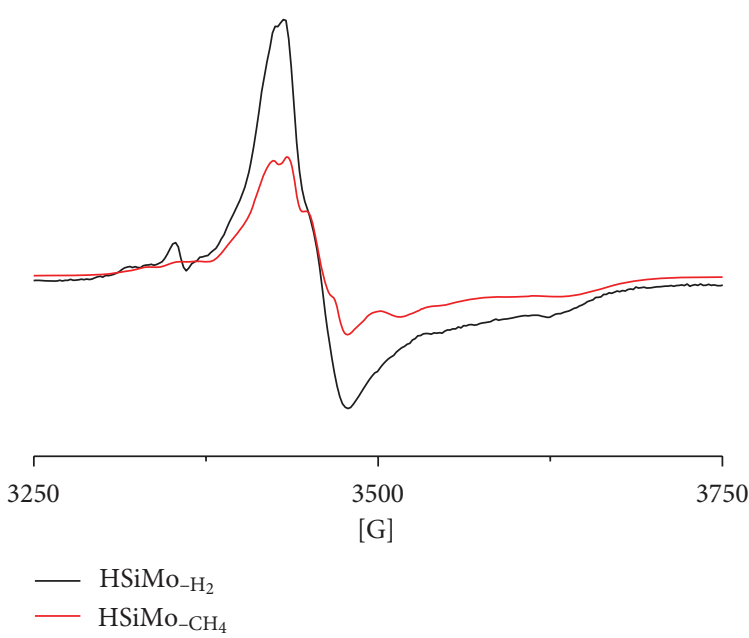

FIGURE 4: ESR spectra of: (a) $\mathrm{HSiMo} / \mathrm{SiO}_{2}$ reduced with $\mathrm{H}_{2}$ at $150^{\circ} \mathrm{C}$ and (b) $\mathrm{HSiMo} / \mathrm{SiO}_{2}$ after reaction with $\mathrm{CH}_{4}$ at $200^{\circ} \mathrm{C}$.

Clearly, the methane activation on the polyoxometalate can occur already at room temperature and the amount of activated alkane increases rapidly with temperature. At low temperatures, propane is activated more easily than methane (e.g., at room temperature by a factor of 3), in agreement with the lower $\mathrm{C}-\mathrm{H}$ bond energy of this compound $\left(\Delta \mathrm{H}_{\mathrm{C}-\mathrm{H}}^{\circ}\right.$ $=439 \mathrm{~kJ} / \mathrm{mol}$ for $\mathrm{CH}_{3}-\mathrm{H}$ and $413 \mathrm{~kJ} / \mathrm{mol}$ for $\left.\left(\mathrm{CH}_{3}\right)_{2} \mathrm{C}-\mathrm{H}\right)$. However, at higher temperatures this difference becomes smaller and the two molecules are activated quite at the same rate.

Upon treatment with alkanes, all molybdenumcontaining samples turned from yellowish to dark green suggesting a $\mathrm{Mo}(\mathrm{VI})$ reduction. A control sample of $\mathrm{HSiMo} / \mathrm{SiO}_{2}$ was, therefore, reduced under $\mathrm{H}_{2}$ at $150^{\circ} \mathrm{C}$ and analyzed by ESR together with the same sample heated under methane at $200^{\circ} \mathrm{C}$ (Figure 4 ).

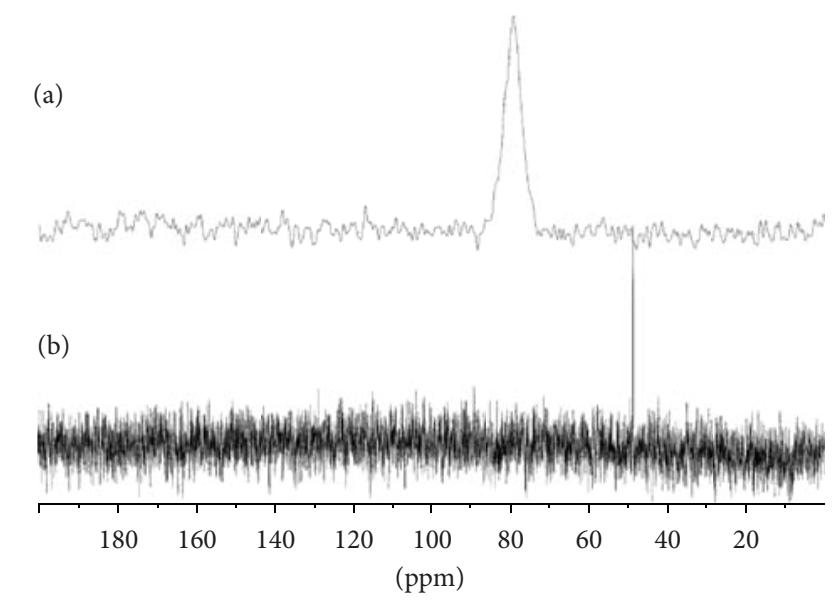

Figure 5: (a) ${ }^{13} \mathrm{C}$ CP-MAS NMR spectra of the reaction product of ${ }^{13} \mathrm{C}-\mathrm{CH}_{4}$ with $\mathrm{HSiMo} / \mathrm{SiO}_{2}$ at $200^{\circ} \mathrm{C}$, (b) ${ }^{13} \mathrm{C}$ solution $\mathrm{NMR}$ spectrum after reaction of sample (a) with $\mathrm{D}_{2} \mathrm{O}\left(24 \mathrm{~h}\right.$ at $\left.60^{\circ} \mathrm{C}\right)$.

The spectra obtained after the reduction under hydrogen is quite comparable to those reported in the literature [31] and corresponds to a $\mathrm{Mo}(\mathrm{V})$ species. The spectrum obtained after reaction of $\mathrm{HSiMo} / \mathrm{SiO}_{2}$ with $\mathrm{CH}_{4}$ at $200^{\circ} \mathrm{C}$ can also be attributed to a $\mathrm{Mo}(\mathrm{V})$ species. However, the hyperfine structure is different from that observed after reduction under hydrogen and could be due to a slightly different environment around molybdenum(V) or, as in [31] to a different concentration of $\mathrm{Mo}(\mathrm{V})$ species.

The presence of $\mathrm{Mo}(\mathrm{V})$ can be explained by (i) a reaction mechanism involving an acid reaction of $\mathrm{CH}_{4}$ with the protons of the polyacid and a further reduction of the polyacid by the evolved hydrogen or (ii) a direct two-electron reduction of the polyacid by $\mathrm{CH}_{4}$ (called redox reaction above). However, neutral salts of molybdic polyoxometalates (such as $\mathrm{K}_{3} \mathrm{PMo}_{12} \mathrm{O}_{40}$ ) do not activate methane at moderate temperature, showing that protons are necessary for this reaction. Moreover, the two-electron reduced polyoxometalate formed via the redox reaction should not be paramagnetic, the two electrons being coupled in such derivatives [32] and should not give an ESR signal. We can then conclude that the reaction pathway of methane activation on the polyoxometalate is mainly a reaction with protons. This reaction proceeds at low temperature. This reaction can be accompanied by a reduction of molybdenum(VI) (by the evolved hydrogen and/or a redox process).

3.2. Characterization of the "Activated Methane Species". In order to better understand what happened on the polyoxometalate surface, we performed the reaction of $\mathrm{HSiMo} / \mathrm{SiO}_{2}$ with ${ }^{13} \mathrm{CH}_{4}$ and studied the resulting solid by ${ }^{13} \mathrm{C} \mathrm{CP}$ MAS NMR. After activation at $200^{\circ} \mathrm{C}$, the NMR spectrum shows unambiguously a relatively broad signal at $77 \mathrm{ppm}$ (Figure 5(a)). This chemical shift is uncommon for the methoxy species which should be expected for a $\mathrm{Me}^{+}$cation interacting with a polyoxometalate. For example, methoxy species are observed at around 55-60 ppm on zeolites [3335]. Methoxy species were also synthesized on $\mathrm{H}_{3} \mathrm{PW}_{12} \mathrm{O}_{40}$ 
by reacting the solid with vapors of methanol at room temperature [36, 37]. These species were characterized by solid-state ${ }^{13} \mathrm{C}$ NMR and led to a signal at ca. 55-60 ppm, as on zeolites. The direct methylation of organic salts of $\left[\mathrm{PMo}_{12} \mathrm{O}_{40}\right]^{3-}$ and $\left[\mathrm{PW}_{12} \mathrm{O}_{40}\right]^{3-}$ by $\left(\mathrm{CH}_{3}\right)_{3} \mathrm{OBF}_{4}$ in $1,2-$ dichloroethane was also reported by Knoth and Harlow [38]. While the tungstic heteropolyoxometalate did not lead to a clean reaction, the trimethyloxonium salt being the main product, the molybdic compound led to the formation of the methylated compound $\left[\mathrm{PMo}_{12} \mathrm{O}_{40}\left(\mathrm{CH}_{3}\right)\right]^{2-}$ which was characterized by Knoth and Harlow by single-crystal X-ray crystallography [38]. In this compound, the methyl group is not located on a terminal oxygen atom but on an edgeshared one. Unfortunately, no ${ }^{13} \mathrm{C}$ NMR data were available for this species. So we synthesized it and recorded its ${ }^{13} \mathrm{C}$ NMR spectrum. However, due to the high amount of organic cations, no clear information could be deduced from this study. All attempts to replace the organic cation by an inorganic one failed. We decided then to synthesize the ${ }^{13} \mathrm{C}$ enriched compound by performing an exchange reaction with ${ }^{13} \mathrm{CH}_{3} \mathrm{OH}$. Indeed, it is well known that the oxygen atoms of $\left[\mathrm{PMo}_{12} \mathrm{O}_{40}\right]^{3-}$ can be easily exchanged in water at room temperature $[39,40]$. It seemed then logical that such an exchange reaction should also occur, even partially, with methanol:

$$
\begin{aligned}
& {\left[\mathrm{PMo}_{12} \mathrm{O}_{40}\left(\mathrm{CH}_{3}\right)\right]^{2-}+{ }^{13} \mathrm{CH}_{3} \mathrm{OH}} \\
& \longrightarrow\left[\mathrm{PMo}_{12} \mathrm{O}_{40}\left({ }^{13} \mathrm{CH}_{3}\right)\right]^{2-}+\mathrm{CH}_{3} \mathrm{OH}
\end{aligned}
$$

For this purpose, $0.2 \mathrm{~g}$ of the Knoth salt were solubilized in $2 \mathrm{~mL}$ of $\mathrm{CH}_{3} \mathrm{CN}$ in presence of $0.1 \mathrm{~mL}$ of ${ }^{13} \mathrm{CH}_{3} \mathrm{OH}$ and the solution was kept at room temperature overnight. A partial exchange occurred as evidenced by ${ }^{13} \mathrm{C}$ NMR. The ${ }^{13} \mathrm{C}$ solution NMR spectrum of the ${ }^{13} \mathrm{C}$ partially exchanged salt did not show any signal in the 55-60 ppm range which could be ascribed to a methoxy species but a peak was observed at $74.5 \mathrm{ppm}$. Such a value is not so surprising for a methyl group linked to a triply coordinated oxygen atom as, for example, the trimethyloxonium salt gives a signal at ca. $80 \mathrm{ppm}$ both in superacid solution and on the surface of acidic zeolites [37]. The great analogy between this peak and that observed after methane activation allows us to propose that the species formed after methane activation on $\mathrm{H}_{4} \mathrm{SiMo}_{12} \mathrm{O}_{40}$ was a methyl group linked to an edge-shared bridging atom of the polyoxometalate. A simultaneous formation of $\mathrm{Mo}-\mathrm{O}-\mathrm{CH}_{3}$ species on terminal oxygen atoms cannot be excluded, but if they are formed they should have been decomposed at the reaction temperature $\left(200^{\circ} \mathrm{C}\right)$.

3.3. Synthesis of the "Activated Methane Species" by Reaction with Methanol. Luzgin et al. [37] and Zhang et al. [36] have reported that the reaction of methanol with $\mathrm{H}_{3} \mathrm{PW}_{12} \mathrm{O}_{40}$ led to the formation of methoxy species on the polyoxometalate. When looking at the above conclusions, these species should be the same as those obtained by activation of methane on the polyoxometalate. In order to confirm our attributions, we have then studied by solid-state ${ }^{13} \mathrm{C}$ CP-MAS NMR the

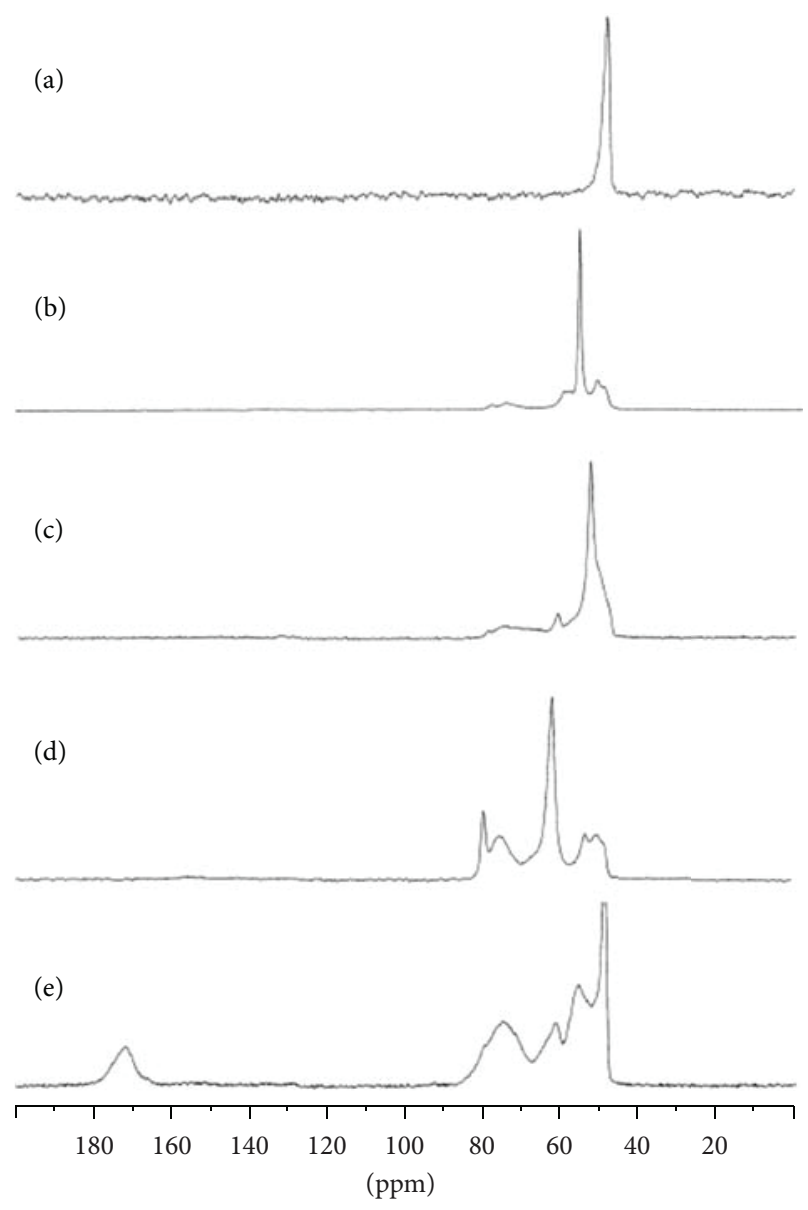

FIGURE 6: ${ }^{13} \mathrm{C}$ CP-MAS NMR spectra of the solids obtained after: (a) reaction of ${ }^{13} \mathrm{CH}_{3} \mathrm{OH}$ on $\mathrm{SiO}_{2}$ at $200^{\circ} \mathrm{C}$ and evacuation at $60^{\circ} \mathrm{C}$; (b) adsorption of ${ }^{13} \mathrm{CH}_{3} \mathrm{OH}$ on bulk $\mathrm{HSiW}$ and evacuation at $60^{\circ} \mathrm{C}$; (c) adsorption of ${ }^{13} \mathrm{CH}_{3} \mathrm{OH}$ on $\mathrm{HSiW} / \mathrm{SiO}_{2}$ and evacuation at $60^{\circ} \mathrm{C}$; (d) same as (c) but evacuation at $120^{\circ} \mathrm{C}$; (e) adsorption of ${ }^{13} \mathrm{CH}_{3} \mathrm{OH}$ on $\mathrm{HSiMo} / \mathrm{SiO}_{2}$ and evacuation at $60^{\circ} \mathrm{C}$.

reaction products of ${ }^{13} \mathrm{C}$-methanol with the silica-supported polyoxometalates. Blanks were made with silica alone (as it is known that methanol can react with the hydroxyl groups of silica) and with bulk $\mathrm{H}_{4} \mathrm{SiW}_{12} \mathrm{O}_{40}$. The results are shown in Figure 6.

Quite the same peaks are seen for all samples, at 48 , $52,54,62,77$, and $80 \mathrm{ppm}$. The signal at $48 \mathrm{ppm}$ is present only for the supported samples while an additional peak at $58 \mathrm{ppm}$ is observed for bulk $\mathrm{H}_{4} \mathrm{SiW}_{12} \mathrm{O}_{40}$ and a new signal appears at ca. $170 \mathrm{ppm}$ for the $\mathrm{HSiMo} / \mathrm{SiO}_{2}$ sample. Clearly the signal at $48 \mathrm{ppm}$ can be ascribed to a methoxy group on silica $\equiv \mathrm{Si}-\mathrm{O}-\mathrm{CH}_{3}$ as it corresponds to what is observed on silica treated with methanol (Figure 6(a)). The signals at 80 and $62 \mathrm{ppm}$ increase with the reaction temperature, and in agreement with Luzgin et al. [37] we attribute them to the trimethyloxonium ion $\left(\mathrm{CH}_{3}\right)_{3} \mathrm{O}^{+}$and to dimethyl ether, respectively. The signals at 52 and $54 \mathrm{ppm}$ were attributed to $\mathrm{CH}_{3}-\mathrm{O}-\mathrm{W}$ species by Luzgin. Zhang et al. proposed, on the basis of DFT calculations and REDOR experiments, that these two peaks corresponded to methyl groups on 
terminal and bridging oxygen atoms of the polyoxometalate, respectively [36]. However, it does not seem reasonable to attribute a chemical shift at ca. $55 \mathrm{ppm}$ for a methyl group on a bridging oxygen atom. Indeed, our above results indicate that the relatively broad signal at $77 \mathrm{ppm}$ must be attributed to the methyl group on the bridging oxygen atom, the signals at 52 and $54 \mathrm{ppm}$ being then due to a methyl group on two different terminal oxygen atoms of the polyoxometalate. In agreement with our attribution, Luzgin et al. studied the carbonylation of dimethyl ether on $\mathrm{Rh} / \mathrm{Cs}_{2} \mathrm{HPW}_{12} \mathrm{O}_{40}$ and attributed a signal near $75 \mathrm{ppm}$ to a methyl group on a Cs-O-W bridging atom $[41,42]$. However, the most interesting feature of these studies is the presence of the peak at ca. $170 \mathrm{ppm}$ in the case of $\mathrm{HSiMo} / \mathrm{SiO}_{2}$. This signal corresponds to formaldehyde and so to the oxidation product of the methoxy group by the polyoxometalate. This reaction proceeds at relatively low temperature $\left(60^{\circ} \mathrm{C}\right)$ on $\mathrm{HSiMo} / \mathrm{SiO}_{2}$ but does not occur on $\mathrm{HSiW} / \mathrm{SiO}_{2}$ even after heating at $120^{\circ} \mathrm{C}$, in agreement with the higher reducibility of molybdic polyanions. These experiments cannot allow to determine what methoxy species (on terminal or bridging oxygen) has reacted but some indications can be found in the work of Waters et al. who studied the gas phase oxidation of methanol to formaldehyde [43] and in the results of the methane activation by $\mathrm{HSiMo} / \mathrm{SiO}_{2}$. They observed that the reaction occurred only on binuclear dimolybdate centers, the mononuclear centers being inactive. As the reaction of methane with $\mathrm{HSiMo} / \mathrm{SiO}_{2}$ gives only the methoxy group on the bridging oxygen atom (Figure 5) while the two species could be expected, it seems reasonable to propose that the species which is oxidized is localized on a terminal oxygen atom, the oxygen atom involved in the oxidation process being a bridging one. It should finally be pointed out that the oxidation of the methoxy group on the polyoxometalate is necessary accompanied by the reduction of the polyoxometalate and so by the formation of $\mathrm{Mo}(\mathrm{V})$.

3.4. Reaction of a (Methane + Oxygen) Mixture on Polyoxometalates. As the objective is to perform methane oxidation, we studied also the reaction of methane and oxygen on the different polyoxometalates. This study was made as for the data of Figures 1 and 2 by passing a mixture of $\mathrm{CH}_{4}$ and $\mathrm{O}_{2}$ on the polyoxometalate and increasing the temperature. As for methane alone, only $\mathrm{CO}_{2}$ was detected and its value is given in Figure 2 and compared to that obtained without oxygen in the same conditions. It can be seen that, with the exception of $\mathrm{H}_{4} \mathrm{PVMo}_{11} \mathrm{O}_{40}$, the amount of $\mathrm{CO}_{2}$ is quite the same in the two cases for temperatures below ca. $400^{\circ} \mathrm{C}$, a difference being observed only at higher temperatures. For molybdic compounds, the values are exactly the same while for tungstic compounds there is an increase by a factor 2 . These data show unambiguously that at temperatures below $400^{\circ} \mathrm{C}$ the reaction is not catalytic. This can be explained simply if we assume that the first step is the attack of methane by a proton of the polyacid and evolution of hydrogen. Indeed, the starting polyoxometalate can then be restored only in presence of protons. At temperatures higher than $400^{\circ} \mathrm{C}$, the polyoxometalate has lost its protons and the mechanism is probably of the redox type, without needing introduction of hydrogen source. These conclusions are in agreement with literature data: the industrial oxidation of methanol to formaldehyde over solid-state molybdenum(VI) oxide catalysts occurs only at elevated temperatures [44]. In that case the rate determining step was the oxidation of the methoxo ligand, a reaction which occurs at low temperature on the polyoxometalate. The oxidation of methane to formaldehyde on silicomolybdic supported on silica occurs at high temperature and in presence of water [45]. An interesting feature is the result obtained with $\mathrm{H}_{4} \mathrm{PVMo}_{11} \mathrm{O}_{40} / \mathrm{SiO}_{2}$ : indeed in presence of oxygen the $\mathrm{CO}_{2}$ evolution begins at the same temperature than without oxygen but increases rapidly with the temperature, probing that the reaction becomes catalytic in these conditions. Our data cannot give indications on the mechanism and why this polyoxometalate has such a behaviour. This could be due to the fact that it can be reoxidized more easily than the molybdic compounds. Water evolved during the oxidation process of methane to $\mathrm{CO}_{2}$ could help to restore the polyoxometalate.

3.5. Reaction of the "Activated Methane Species" with Water. When looking at the equation describing the exchange between unlabeled and labeled methanol on the polyoxometalate, it seems logical to think that labeled methanol could be replaced by water. In that case methanol should evolve and the starting polyoxometalate should be restored. This could give the following catalytic cycle:

$$
\begin{aligned}
\mathrm{H}_{n}\left[\mathrm{XM}_{12} \mathrm{O}_{40}\right]+\mathrm{CH}_{4} \longrightarrow \mathrm{H}_{n}-1[ & \left.\mathrm{XM}_{12} \mathrm{O}_{40}\left(\mathrm{CH}_{3}\right)\right]+\mathrm{H}_{2} \\
\mathrm{H}_{n}-1\left[\mathrm{XM}_{12} \mathrm{O}_{40}\left(\mathrm{CH}_{3}\right)\right]+\mathrm{H}_{2} \mathrm{O} \longrightarrow & \mathrm{H}_{n}\left[\mathrm{XM}_{12} \mathrm{O}_{40}\right] \\
+ & \mathrm{CH}_{3} \mathrm{OH}
\end{aligned}
$$

Such a reaction should be very interesting as it could operate without oxygen and lead to the formation of hydrogen and methanol from methane and water. Even if thermodynamics is not in agreement with this reaction (but from a practical point of view the use of membrane reactors trapping hydrogen could displace the equilibrium), there are also limitations due to the catalytic system itself: (i) It is well known that ${ }^{16} \mathrm{O} /{ }^{17} \mathrm{O}$ exchange in polyoxometalates can be made simply by putting the polyoxometalate in a $\mathrm{H}_{2}{ }^{17} \mathrm{O}$ solution at room temperature for molybdic compounds while it is necessary to heat at high temperature for tungstic compounds. As a consequence, the exchange reaction could occur only at high temperature for tungstic compounds while lower temperatures could be expected for molybdic compounds; (ii) for molybdic compounds the reaction of methane with the protons leads to the formation of hydrogen which can reduce the polyoxometalate. Similarly the oxidation of the terminal methoxy groups (which occurs at low temperature) will also lead to the formation of reduced species. As a consequence, a reoxidation step by oxygen is necessary; (iii) finally the second reaction (reaction of the methoxy group with water) is strongly displaced to the left, the methoxy species being very stable. This can be shown simply: the sample obtained after activation of methane with $\mathrm{HSiMo} / \mathrm{SiO}_{2}$ (and 
which gave the spectrum shown in Figure 5(a)) was put in water at $60^{\circ} \mathrm{C}$ during $24 \mathrm{~h}$ and the spectrum of the solution was recorded. Only traces of methanol were detected by NMR of the solution (Figure 5(b)). One explanation could be that the hydrophobic effect of the methyl group had prevented the attack by the water molecule.

\section{Conclusion}

Methane can be activated under mild conditions on both tungstic and molybdic heteropolyacids. The reaction passes through an attack of the $\mathrm{C}-\mathrm{H}$ bond by a proton of the polyacid and evolution of hydrogen. This hydrogen can then reduce the polyoxometalate. The reduction is mainly observed on molybdic and vanadomolybdic compounds while it is absent (or very small) on tungstic ones. Another reaction path occurring simultaneously and leading to a two-electron reduction of the polyoxometalate can also be present but in that case also protons are needed. The resulting species can be seen as a methoxy-polyoxometalate. Such a species can also be synthesized by reaction of methanol with the anhydrous polyoxometalate. The methyl group can be linked to the polyoxometalate by a terminal or a bridging oxygen atom. In the case of tungstic polyacids, the two species are stable up to $120^{\circ} \mathrm{C}$ while in the case of molybdic compounds oxidation to formyl species occurs even at $60^{\circ} \mathrm{C}$. Only the methoxy species on the terminal oxygen is oxidized. When the reaction is made in presence of oxygen, quite the same results are observed below $400^{\circ} \mathrm{C}$ showing that there is no catalytic reaction the polyoxometalate being not restored. The reaction becomes catalytic only at higher temperatures but in that case the mechanism is probably different. There is one exception, $\mathrm{H}_{4} \mathrm{PVMo}_{11} \mathrm{O}_{40}$, for which the reaction becomes catalytic at low temperature, ca. $200^{\circ} \mathrm{C}$. However, in all cases it will not be possible to obtain methanol only by this way. The only one possibility to obtain only methanol should be to use tungstic heteropolyacids at temperatures around $200-300^{\circ} \mathrm{C}$ in presence of water and in reactors allowing the displacement of the equilibrium.

\section{Conflict of Interests}

The authors declare that there is no financial or competing conflict of interests for this work.

\section{Acknowledgments}

Financial support for presented work was provided by the 7th European Framework Research Program FP7/2007-2013, subvention no. 215193.

\section{References}

[1] J. H. Lunsford, "Catalytic conversion of methane to more useful chemicals and fuels: a challenge for the 21 st century," Catalysis Today, vol. 63, no. 2-4, pp. 165-174, 2000.

[2] M. C. Alvarez-Galvan, N. Mota, M. Ojeda, S. Rojas, R. M. Navarro, and J. L. G. Fierro, "Direct methane conversion routes to chemicals and fuels," Catalysis Today, vol. 171, no. 1, pp. 15-23, 2011.

[3] R. K. Grasselli, "Fundamental principles of selective heterogeneous oxidation catalysis," Topics in Catalysis, vol. 21, no. 1-3, pp. 79-88, 2002.

[4] Y. Moro-Oka, "The role of acidic properties of metal oxide catalysts in the catalytic oxidation," Applied Catalysis A, vol. 181, no. 2, pp. 323-329, 1999.

[5] M. V. Luzgin, A. A. Gabrienko, V. A. Rogov, A. V. Toktarev, V. N. Parmon, and A. G. Stepanov, "The "alkyl" and "carbenium" pathways of methane activation on Ga-modified zeolite BEA: ${ }^{13} \mathrm{C}$ solid-state NMR and GC-MS study of methane aromatization in the presence of higher alkane," Journal of Physical Chemistry C, vol. 114, no. 49, pp. 21555-21561, 2010.

[6] E. V. Starokon, M. V. Parfenov, L. V. Pirutko, S. I. Abornev, and G. I. Panov, "Room-temperature oxidation of methane by $\alpha$ oxygen and extraction of products from the FeZSM-5 surface," Journal of Physical Chemistry C, vol. 115, no. 5, pp. 2155-2161, 2011.

[7] K. Kwapien, M. Sierka, J. Döbler, and J. Sauer, "Reactions of $\mathrm{H}_{2}, \mathrm{CH}_{4}, \mathrm{C}_{2} \mathrm{H}_{6}$, and $\mathrm{C}_{3} \mathrm{H}_{8}$ with $\left[(\mathrm{MgO})_{n}\right]^{+}$clusters studied by density functional theory," ChemCatChem, vol. 2, no. 7, pp. 819-826, 2010.

[8] R. A. Periana, D. J. Taube, E. R. Evitt et al., "A mercury-catalyzed, high-yield system for the oxidation of methane to methanol," Science, vol. 259, no. 5093, pp. 340-343, 1993.

[9] R. A. Periana, D. J. Taube, S. Gamble, H. Taube, T. Satoh, and H. Fujii, "Platinum catalysts for the high-yield oxidation of methane to a methanol derivative," Science, vol. 280, no. 5363, pp. 560-564, 1998.

[10] C. J. Jones, D. Taube, V. R. Ziatdinov et al., "Selective oxidation of methane to methanol catalyzed, with $\mathrm{C}-\mathrm{H}$ activation, by homogeneous, cationic gold," Angewandte Chemie, vol. 43, no. 35, pp. 4626-4629, 2004.

[11] C. L. Hill, "Introduction: polyoxometalates multicomponent molecular vehicles to probe fundamental issues and practical problems," Chemical Reviews, vol. 98, pp. 1-390, 1998.

[12] G. I. Kapustin, T. R. Brueva, A. L. Klyachko, M. N. Timofeeva, S. M. Kulikov, and I. V. Kozhevnikov, "Study of the acidity of heteropolyacids," Kinetics and Catalysis, vol. 31, no. 4, pp. 896-898, 1991.

[13] F. Lefebvre, " ${ }^{31} \mathrm{P}$ MAS NMR study of $\mathrm{H}_{3} \mathrm{PW}_{12} \mathrm{O}_{40}$ supported on silica: formation of $\left(\equiv \mathrm{SiOH}_{2}^{+}\right)\left(\mathrm{H}_{2} \mathrm{PW}_{12} \mathrm{O}_{40}^{-}\right)$," Journal of the Chemical Society, Chemical Communications, no. 10, pp. 756-757, 1992.

[14] E. Grinenval, X. Rozanska, A. Baudouin et al., "Controlled interactions between anhydrous keggin-type heteropolyacids and silica support: preparation and characterization of welldefined silica-supported polyoxometalate species," Journal of Physical Chemistry C, vol. 114, no. 44, pp. 19024-19034, 2010.

[15] A. Thomas, C. Dablemont, J. M. Basset, and F. Lefebvre, "Comparison of $\mathrm{H}_{3} \mathrm{PW}_{12} \mathrm{O}_{40}$ and $\mathrm{H}_{4} \mathrm{SiW}_{12} \mathrm{O}_{40}$ heteropolyacids supported on silica by ${ }^{1} \mathrm{H}$ MAS NMR," Comptes Rendus Chimie, vol. 8, no. 11-12, pp. 1969-1974, 2005.

[16] V. Dufaud and F. Lefebvre, "Inorganic hybrid materials with encapsulated polyoxometalates," Materials, vol. 3, pp. 682-703, 2010.

[17] V. Dufaud, F. Lefebvre, G. P. Niccolai, and M. Aouine, "New insights into the encapsulation and stabilization of heteropolyacids inside the pore walls of mesostructured silica materials," Journal of Materials Chemistry, vol. 19, no. 8, pp. 1142-1150, 2009. 
[18] T. Okuhara, H. Watanabe, T. Nishimura, K. Inumaru, and M. Misono, "Microstructure of cesium hydrogen salts of 12 tungstophosphoric acid relevant to novel acid catalysis," Chemistry of Materials, vol. 12, no. 8, pp. 2230-2238, 2000.

[19] S. Kasztelan and J. B. Moffat, "The oxidation of methane on heteropolyoxometalates. I. Catalytic properties of silicasupported heteropolyacids," Journal of Catalysis, vol. 106, no. 2, pp. 512-524, 1987.

[20] S. Ahmed and J. B. Moffat, "Methane conversion on silicasupported 12-molybdophosphoric acid in the presence of dichloro- or tetrachloromethane," Journal of Physical Chemistry, vol. 93, no. 6, pp. 2542-2548, 1989.

[21] N. Mizuno, H. Ishige, Y. Seki et al., "Low-temperature oxygenation of methane into formic acid with molecular oxygen in the presence of hydrogen catalysed by $\mathrm{Pd}_{0.08} \mathrm{Cs}_{2.5} \mathrm{H}_{1.34} \mathrm{PVMo}_{11} \mathrm{O}_{40}$," Chemical Communications, no. 14, pp. 1295-1296, 1997.

[22] J. S. Min, H. Ishige, M. Misono, and N. Mizuno, "Lowtemperature selective oxidation of methane into formic acid with $\mathrm{H}_{2}-\mathrm{O}_{2}$ gas mixture catalyzed by bifunctional catalyst of palladium-heteropoly compound," Journal of Catalysis, vol. 198, no. 1, pp. 116-121, 2001.

[23] T. Sugino, A. Kido, N. Azuma, A. Ueno, and Y. Udagawa, "Partial oxidation of methane on silica-supported silicomolybdic acid catalysts in an excess amount of water vapor," Journal of Catalysis, vol. 190, no. 1, pp. 118-127, 2000.

[24] S. Pei, B. Yue, L. Qian et al., "Preparation and characterization of P-Mo-V mixed oxide-incorporating mesoporous silica catalysts for selective oxidation of methane to formaldehyde," Applied Catalysis A, vol. 329, pp. 148-155, 2007.

[25] O. Benlounes, S. Mansouri, C. Rabia, and S. Hocine, "Direct oxidation of methane to oxygenates over heteropolyanions," Journal of Natural Gas Chemistry, vol. 17, no. 3, pp. 309-312, 2008.

[26] N. D. Spencer and C. J. Pereira, " $\mathrm{V}_{2} \mathrm{O}_{5} \mathrm{SiO}_{2}$-catalyzed methane partial oxidation with molecular oxygen," Journal of Catalysis, vol. 116, no. 2, pp. 399-406, 1989.

[27] N. Mizuno and K. Kamata, "Catalytic oxidation of hydrocarbons with hydrogen peroxide by vanadium-based polyoxometalates," Coordination Chemistry Reviews, vol. 255, no. 19-20, pp. 2358-2370, 2011.

[28] S. Berndt, D. Herein, F. Zemlin, E. Beckmann, G. Weinberg, and J. Schütze, "A new unifying structural model of heteropolymolybdate salts: microstructure and thermal stability of a series of molecular oxides," Physical Chemistry Chemical Physics, vol. 102, no. 5, pp. 763-774, 1998.

[29] E. Grinenval, J. M. Basset, and F. Lefebvre, "Reactivity of anhydrous Keggin-type heteropolyacids with alkylsilanes: synthesis and characterization," Inorganic Chemistry, vol. 49, no. 19, pp. 8749-8755, 2010.

[30] E. Grinenval, J. M. Basset, and F. Lefebvre, "Reactivity of anhydrous Keggin-type molybdenum heteropolyacids with alkylsilanes: synthesis and characterization," Inorganica Chimica Acta, vol. 370, no. 1, pp. 297-303, 2011.

[31] M. Otake, Y. Komiyama, and T. Otaki, "Electron spin resonance studies of the reduced molybdovanadophosphoric heteropoly acids. I," Journal of Physical Chemistry, vol. 77, no. 24, pp. 2896-2903, 1973.

[32] C. De Graaf, R. Caballol, S. Romo, and J. M. Poblet, "Ab initio study of the singlet-triplet splitting in reduced polyoxometalates," Theoretical Chemistry Accounts, vol. 123, no. 1-2, pp. 3-10, 2009.
[33] V. Bosáček, "Formation of surface-bonded methoxy groups in the sorption of methanol and methyl iodide on zeolites studied by ${ }^{13}$ C MAS NMR spectroscopy," Journal of Physical Chemistry, vol. 97, no. 41, pp. 10732-10737, 1993.

[34] D. K. Murray, J. W. Chang, and J. F. Haw, "Conversion of methyl halides to hydrocarbons on basic zeolites: a discovery by in Situ NMR," Journal of the American Chemical Society, vol. 115, no. 11, pp. 4732-4741, 1993.

[35] W. Wang, M. Seiler, and M. Hunger, "Role of surface methoxy species in the conversion of methanol to dimethyl ether on acidic zeolites investigated by in situ stopped-flow MAS NMR spectroscopy," Journal of Physical Chemistry B, vol. 105, no. 50, pp. 12553-12558, 2001.

[36] H. Zhang, A. Zheng, H. Yu, S. Li, X. Lu, and F. Deng, "Formation, location, and photocatalytic reactivity of methoxy species on keggin $12-\mathrm{H}_{3} \mathrm{PW}_{12} \mathrm{O}_{40}$ : a joint solid-state NMR spectroscopy and DFT calculation study," Journal of Physical Chemistry C, vol. 112, no. 40, pp. 15765-15770, 2008.

[37] M. V. Luzgin, M. S. Kazantsev, W. Wang, and A. G. Stepanov, "Reactivity of methoxy species toward $\mathrm{CO}$ on keggin 12$\mathrm{H}_{3} \mathrm{PW}_{12} \mathrm{O}_{40}$ : a study with solid state NMR," Journal of Physical Chemistry C, vol. 113, no. 45, pp. 19639-19644, 2009.

[38] W. H. Knoth and R. L. Harlow, "Derivatives of heteropolyanions. 3. O-alkylation of $\mathrm{Mo}_{12} \mathrm{PO}_{403}$ - and $\mathrm{W}_{12} \mathrm{PO}_{403}$-," Journal of the American Chemical Society, vol. 103, no. 14, pp. 4265-4266, 1981.

[39] I. V. Kozhevnikov, A. Sinnema, and H. van Bekkum, "Proton sites in Keggin heteropoly acids from ${ }^{17} \mathrm{O}$ NMR," Catalysis Letters, vol. 34, no. 1-2, pp. 213-221, 1995.

[40] I. V. Kozhevnikov, A. Sinnema, H. Van Bekkum, and M. Fournier, "17 O MASNMR study of 12-molybdophosphoric acid," Catalysis Letters, vol. 41, no. 3-4, pp. 153-157, 1996.

[41] M. S. Kazantsev, M. V. Luzgin, G. G. Volkova, and A. G. Stepanov, "Carbonylation of dimethyl ether on $\mathrm{Rh} / \mathrm{Cs}_{2} \mathrm{HP}$ ${ }_{12} \mathrm{O}_{40}$ : solid-state NMR study of the mechanism of reaction in the presence of a methyl iodide promoter," Journal of Catalysis, vol. 291, pp. 9-16, 2012.

[42] M. V. Luzgin, M. S. Kazantsev, G. G. Volkova, W. Wang, and A. G. Stepanov, "Carbonylation of dimethyl ether on solid Rhpromoted Cs-salt of Keggin 12- $\mathrm{H}_{3} \mathrm{PW}_{12} \mathrm{O}_{40}$ : a solid-state NMR study of the reaction mechanism," Journal of Catalysis, vol. 277, no. 1, pp. 72-79, 2011.

[43] T. Waters, R. A. J. O’Hair, and A. G. Wedd, "Catalytic gas phase oxidation of methanol to formaldehyde," Journal of the American Chemical Society, vol. 125, no. 11, pp. 3384-3396, 2003.

[44] T. Waters, R. A. J. O’Hair, and A. G. Wedd, "Probing the catalytic oxidation of alcohols via an anionic dimolybdate centre using multistage mass spectrometry," Chemical Communications, no. 3, pp. 225-226, 2000.

[45] T. Sugino, A. Kido, N. Azuma, A. Ueno, and Y. Udagawa, "Partial oxidation of methane on silica-supported silicomolybdic acid catalysts in an excess amount of water vapor," Journal of Catalysis, vol. 190, no. 1, pp. 118-127, 2000. 

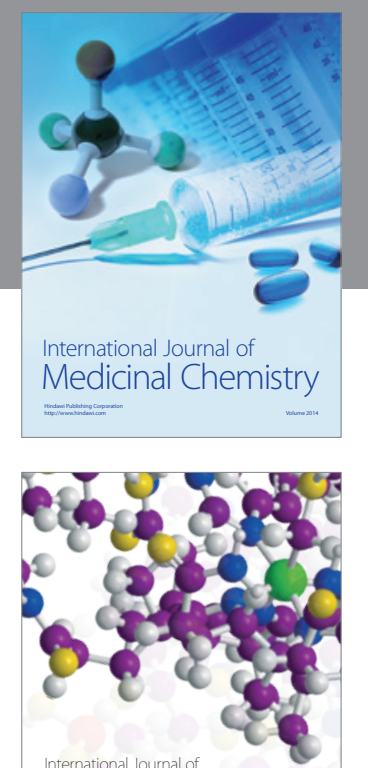

\section{Carbohydrate} Chemistry

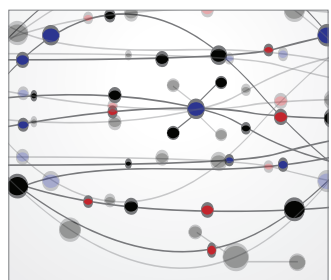

The Scientific World Journal
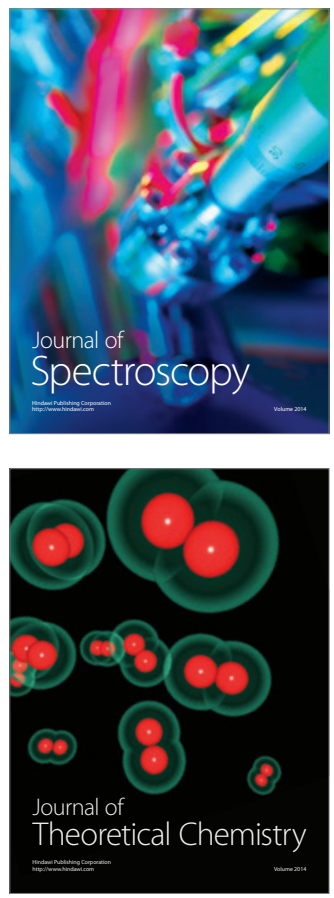
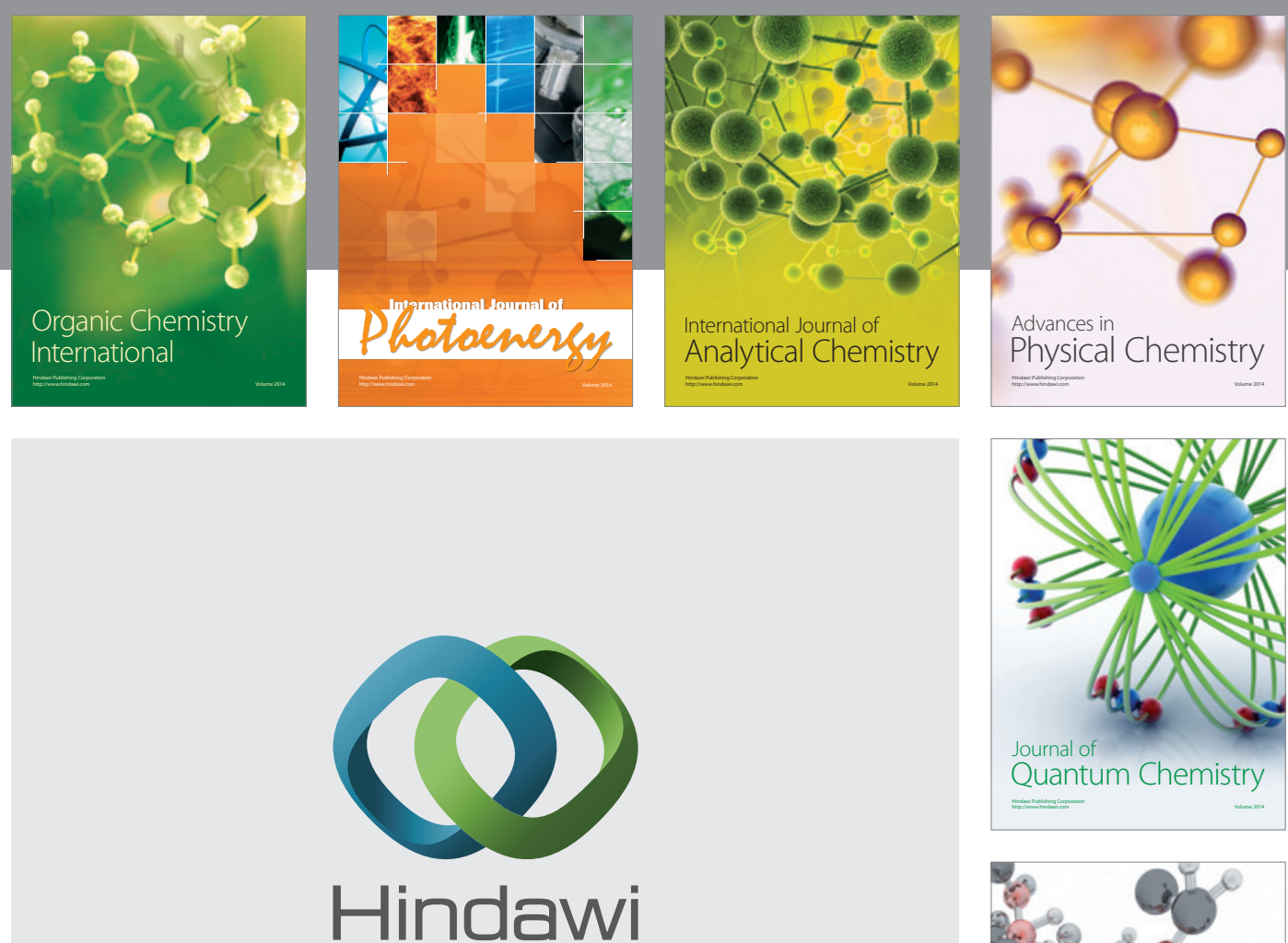

Submit your manuscripts at

http://www.hindawi.com

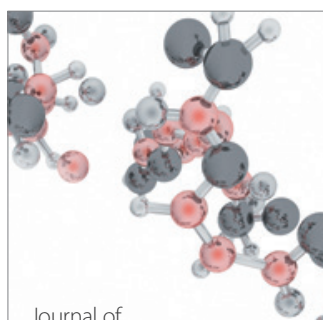

Analytical Methods

in Chemistry

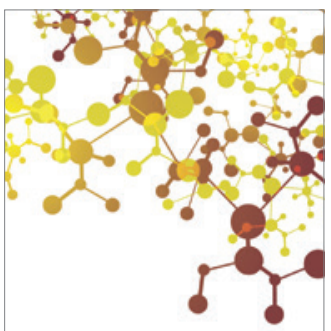

Journal of

Applied Chemistry

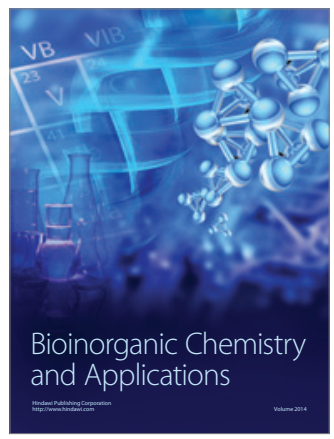

Inorganic Chemistry
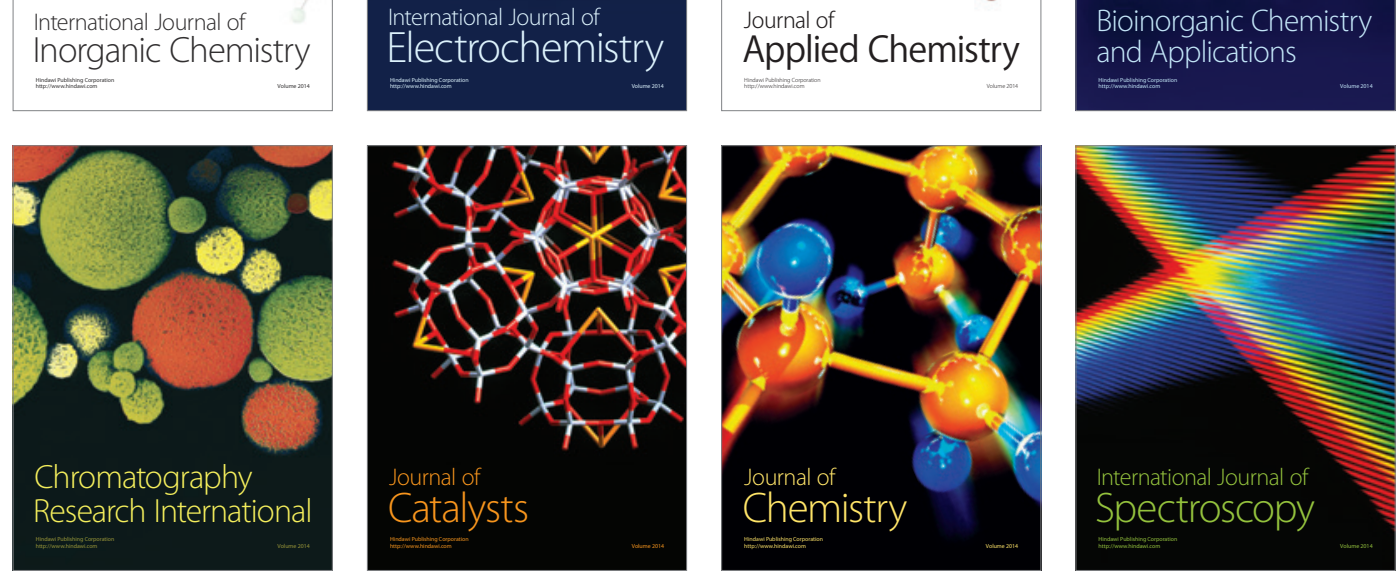